\title{
Leveraging the Power of High-throughput Technologies for Chromatographical Purification
}

\section{Dilara Baş ${ }^{1}$, Emre Burak Erkal ${ }^{1}$, Ali Özhan Aytekin², Deniz Demirhan $^{1,3 *}$}

${ }^{1}$ Biotechnology Group, Turgut Pharmaceuticals, İstanbul, Turkey

${ }^{2}$ Genetics and Bioengineering Department, Faculty of Engineering, Yeditepe University, Atasehir, Istanbul, Turkey

${ }^{3}$ Department of Natural Sciences, Faculty of Engineering, Acibadem Mehmet Ali

Aydinlar University, Istanbul, Turkey

*Corresponding Author: Deniz Demirhan, Turgut Pharmaceuticals Biotechnology Group/Department of Natural Sciences, Faculty of Engineering, Acibadem Mehmet Ali Aydınlar University, İstanbul, Turkey.
Received: July 28, 2021

Published: September 24, 2021

(C) All rights are reserved by Deniz

Demirhan., et al.

\section{Abstract}

Therapeutic monoclonal antibodies (mAbs) are target-specific proteins used for patients especially suffering from cancer, autoimmune, and inflammatory diseases. Due to the success rate of the mAbs, they are the fastest-growing sector in the biopharmaceutical industry. To be used for the therapeutic purposes, the monoclonal antibodies have to be high purity. A variety of different downstream technologies have recently been evolved to provide high quality monoclonal antibody and biosimilar development with low cost in a shorter time. Recent advancements of high-throughput process (HTP) technology are employed for process development for saving time, investment, and cost. HTP allows running large number of experiments in a minimal scale. Incorporation of HTP technology with Design of Experiment (DoE) is systematic integration for effective and rapid screening of optimum experimental conditions.

Development of purification process for mAbs requires the consideration of many different parameters including removal of impurities and ready availability of raw materials for large-scale production. In this study, a downstream process was developed for one of the best-selling biosimilar mAb (TUR02) coupling HTP technology with DoE tools. TUR02 is an IgG1 which has a high tendency to aggregate. In order to develop Protein A chromatography, firstly appropriate elution buffer had been selected using micro-volume columns. Large range of parameters were screened as buffer type (acetic acid, citric acid, sodium acetate), the concentration of buffer (10 mM-150 mM), and three different Protein A resins. Citric acid (10mM) at pH 3.5 was chosen as suitable elution buffer. A resin with base matrix of methacrylic polymer was chosen from the HTP study and a lab scale experiment with $1 \mathrm{ml}$ column was done to prove the success of the scalability of the HTP technology. After Protein A chromatography, HTP technology was applied to cation exchange chromatography to screen different conditions to be able to further decrease the impurity level. Flow through with overloading mode was followed with the cation exchange screening. Concentration of sodium phosphate-based buffer (10 mM - $50 \mathrm{mM}$ ), working $\mathrm{pH}$ and comparison of strong and weak cation exchange resin were screened by coupling HTP technology and DoE tools. Strong cation exchange resin, $38 \mathrm{mM}$ sodium phosphate and pH 4.5 were selected due to its impurity reduction strength. Scalability of the process was successfully proven using $1 \mathrm{ml}$ pre-packed column. With these conditions, the aggregate and HCP levels were 0.52 and 612 and 0.32 and 234 for $0.1 \mathrm{ml}$ and $1 \mathrm{ml}$ columns, respectively.

Keywords: Monoclonal Antibodies; Chromatography; High-Throughput Technology; Design of Experiment; Protein A Ligand; Cation Exchange 


\section{Abbreviations}

CEX: Cation Exchange; CV: Column Volume; DoE: Design of Experiment; DSP: Downstream Process; DBC: Dynamic Binding Capacity; FDA: Food and Drug Administration; FPLC: Fast Protein Liquid Chromatography; HTP: High-throughput; HTPD: High-throughput Process Development; HMW: High Molecular Weight; HCPs: Host Cell Proteins; ICH: The International Council for Harmonisation of Technical Requirements for Pharmaceuticals for Human Use; LMW: Low Molecular Weight; IgG: Immunoglobulin G; mAbs: Monoclonal Antibodies; PAT: Process Analytical Technology; PA: Protein A; rDNA: Residual DNA; rPA: Residual Protein A.

\section{Introduction}

Mammalian cells are the production horses of the monoclonal antibodies (mAbs) for biopharmaceutical applications. For therapeutic usage, high purity of mAbs has to be achieved which requires an extensive downstream process (DSP) development and optimization. A mAb purification platform consists of many operations such as filtration or centrifugation and the sequence of different chromatography methods. Chromatography is the backbone of DSP to reduce the level of impurities down to the acceptable levels to ensure product safety and effectiveness. Especially for biosimilars, DSP becomes very important to provide the critical quality attributes of the drug product. Efficient DSP is desired to control the product related impurities such as aggregates to meet the innovator specifications [1] as well as and process related impurities such as host cell proteins (HCPs), and residual Protein A (rPA) to meet the regulatory guidelines. Therefore, both modelling and development stages of DSP are crucial for the development of highly biosimilar mAb-drug.

There are a large number of parameters such as $\mathrm{pH}$, loading quantity, and resin type which have significant effect on chromatography performance. In addition to chromatography performance, these parameters can also influence the yield and purity of the $\mathrm{mAb}$ [2]. Therefore, a large numbers of experiments have to be performed at lab-scale to find optimum operation parameters which also requires large amount of material. Lab-scale experiments in the Fast Protein Liquid Chromatography (FPLC) systems also take very long times to screen large number of parameters. One of the key emerging technologies for purification can be achieved by technological platforms based on high-throughput (HTP) technology.
Through the combination of this micro-scale format together with design of experiment (DoE) tools and the analytical measurement techniques can be central to the development and optimization [3]. While DoE offers screening, optimization and robust parameter design [4], HTP technology consisting of pre-packed micro-volume columns provides a large number of parameters to be screened in a shorter period. In this case, lab-scale chromatography can only be used for confirmation studies. High-throughput process development (HTPD) provides screening all DSP parameters as working $\mathrm{pH}$, buffer type, loading concentration and resin type in a shorter time period. HTPD is highly encouraged also by FDA, process analytical technology (PAT) and ICH guidelines since this innovative development can lead to a quality-controlled manufacturing. In biosimilar development, HTPD becomes even more important to provide the critical quality attributes of the selected biosimilar $\mathrm{mAb}$.

Protein A chromatography is the most commonly used capture step in $\mathrm{mAb}$ purification processes. It is the best choice for the first step due to high selectivity to the mAbs and it can provide purity of typically $>95 \%$ with high yield. Protein A resins are basis of all $\mathrm{mAb}$ purification as they are easy to use at both small and large scale with optimized protocols [5] therefore, they are the backbone of many commercial purification processes [6].

The first Protein A resin from Staphylococcus aureus was produced in 1975. All Protein A ligands whether they are native or recombinant Protein, they specifically bind to the Fc region of the IgG $[7,8]$. Both native and recombinant Protein A share the same principle of specificity for Fc region of IgG, but recombinant Protein $\mathrm{A}$ has higher binding capacity due to active single point coupling for Fc region of IgG [7]. Recombinant Protein A is generally expressed in Escherichia coli in order to allow for the production of large quantities. Protein A ligands are coupled with base matrix to be used as affinity column in purification processes [5].

As being an affinity column, Protein A chromatography is an essential and highly expensive step in mAb purification. Due to the presence of a large variety of mAbs in development and manufacturing stages, there is increased variety of Protein A resins in the market. Appropriate Protein A selection is challenging process in $\mathrm{mAb}$ production since it is economically important to provide high yield in the purification step in the market. There are many types of Protein A resin matrices such as highly cross-linked cellulose and 
agarose, controlled pore glass and polymer-based matrices. Highly cross-linked matrices provide the pressure stability of the column during the loading of supernatant [12]. Polymer-based resins give the better process yield with the sharper elution profiles [13]. These features can also vary depending on mAb properties.

Protein A chromatography as a first step can provide the removal of aggregates, host cell proteins (HCP) and host cell DNAs (rDNA). Host cell proteins (HCPs) are the main process related impurities which may have immune reactions in the patients [14]. Host cell proteins can depend on the mammalian cells used in the process as well as the cell culture process itself. Due to the continuous improvement of the upstream processes aiming to push titer higher may lead to higher cell numbers which can cause increase in the HCPs and problems in the downstream applications. Protein A chromatography is useful to reduce HCPs due to the Protein A ligand specificity for the Fc region of the mAb with around 95\% purity [15]. Although, Protein A resin wash is the significant of HCPs clearance after loading, optimization of this is not straightforward as it involves different types of interaction [16]. Therefore, addition of polishing chromatography steps is required to allow the reduction of HCPs, rDNAs and aggregates. Residual Protein A (rPA) which leaches from the Protein A columns is another process-related impurity which needs to be removed for the patient safety and this can be reduced in polishing steps like cation exchange (CEX) or anion exchange (AEX) chromatography.

Cation exchange (CEX) chromatography is an established unit operation in purification of mAbs. Due to its high selectivity for impurities, scalability and robustness, CEX chromatography is used as a part of the polishing step in many processes [17]. Cation exchange resin is made of negatively charged particles. CEX is generally employed to reduce the level of HCPs and mAb aggregation [9].

Protein Aggregation was first observed in the Lumry-Eyring model and it was the most common impurity during mAb-drug like development. Aggregates can be described in different ways including soluble/insoluble, covalent/non-covalent, native/denatured and reversible/non-reversible [18]. The presence of mAb aggregates risk in terms of generation immune responses to the mAb-drug product [19].

Low $\mathrm{pH}$ condition after the Protein A chromatography generally shows the form of aggregation in the pool due to the low $\mathrm{pH}$ exposure $[20,21]$. Like mAb aggregates, residual DNA (rDNA) which is derived from a cell culture process is monitored in order to ensure drug purity and safety [22]. The following chromatography steps like CEX and AEX chromatographies can support to remove of mAb aggregates and rDNA.

There are two types of cation exchangers: strong and weak. The difference between weak and strong cation exchangers differ from the functional groups of the resin (hydroxyl. methyl. carboxyl and sulfhydryl) and the capacity of working $\mathrm{pH}$ range. The principle of strong exchangers is to work independently of $\mathrm{pH}$. On the other hand, weak exchangers are $\mathrm{pH}$-dependent and working range of $\mathrm{pH}$ depends on resin capacity [23]. Selection of operation of loading strategies for CEX chromatography depends on the isoelectric point of the protein to be purified. Isoelectric point ( $\mathrm{pI}$ ) is the $\mathrm{pH}$ at which the protein has no net charge and it shows the property of electric field of the protein. The $\mathrm{pI}$ value can be estimated using the primary sequence of the protein. A protein will be negatively charged at $\mathrm{pH}$ values higher than the $\mathrm{pI}$ of a protein; conversely, it will be positively charged at pH values lower than the pI [24]. CEX chromatography can be operated in two ways; flow-through mode and bind-elute mode. In flow-through mode, which is used in this study, the target protein does not bind to the resin, whereas the impurities are captured. Weakly bound proteins are collected in wash step to increase yield. The impurities appear to bind stronger than the protein when flow-through mode is operated with overloading. Therefore, the usage of flow-through mode depends on both loading amount and $\mathrm{pI}$ of the $\mathrm{mAb}$. High flow can also provide high yield and decreased process time. Design and optimization of CEX chromatography depends on the operating conditions such as working $\mathrm{pH}$, ionic strength of the buffer and properties of the resin $[9,10]$. These are the parameters which can provide removal of HCPs, rDNA, rPA and $\mathrm{mAb}$ aggregates.

This work aimed to develop a scalable high throughput chromatography technique for development of biosimilar mAb TUR02. TUR02 is one of the most used mAbs in cancer indication which have high tendency to aggregate. The biosimilar production of this IgG1 molecule has a worldwide importance to achieve the more economical delivery to the patients. In this work, both Protein A and CEX chromatography are extensively studied. Firstly, HTPD is coupled with DoE tools to find the best elution buffer for Protein A chromatography. Using Protein A pool, cation exchange HTPD screening was applied to achieve highest impurity removal. Selected conditions were transferred to large scale chromatography column for confirmation of the process and to show the success of the removal of impurities like HCPs, rPA and mAb aggregates. The general concept of the HTPD platform used in this study is given in figure 1. 


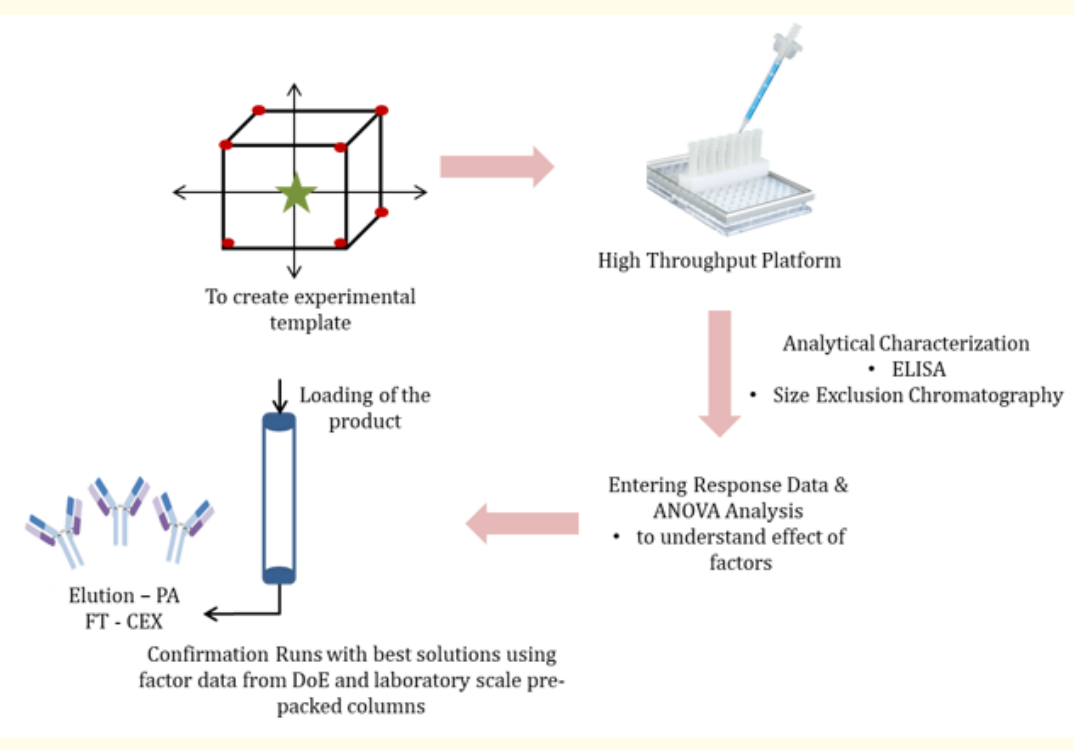

Figure 1: The general concept of HTPD applied in this study.

\section{Materials and Methods}

\section{Information of Protein A resins}

The properties of resins used in this study are shown in table 1. Each Protein A resin has different base matrix to understand effect of any types of elution buffer.
Determination of suitable elution buffer with high-throughput technology

The biosimilar monoclonal antibody TUR02 was initially produced in $3 \mathrm{~L}$ bioreactors and clarified with filtration. In order to find appropriate elution buffer as a first step, HTP technology was

\begin{tabular}{|c|c|c|}
\hline Resin Number & Base Matrix & Protein A Ligand \\
\hline R1 & Methacrylic Polymer & Recombinant Protein A (Escherichia coli) \\
\hline R2 & High-Flow Agarose Beads & Recombinant Protein A (Escherichia coli) \\
\hline R3 & Controlled Pore Glass & Recombinant Native Protein A \\
\hline
\end{tabular}

Table 1: Information regarding to the three different types of Protein A resins.

coupled with DoE tools. Experiment template was designed with Design Expert Software 12 (Stat-Ease. Inc., Minneapolis. MN). A $100 \mu \mathrm{l}(0.5 \mathrm{~cm} \times 0.5 \mathrm{~cm})$ OPUS $^{\circledR}$ PipetColumns (Repligen Corporation) were used for screening with electronic Multipipette ${ }^{\circledR}$ E3x (Eppendorf). Pipet columns containing three different Protein A resins R1, R2 and R3 were used for elution buffer screening. Factors entered in the software were elution buffer type with acetic acid, citric acid and sodium acetate, elution buffer concentration (10 mM-150 mM), pH (3 - 3.8), and three different resin types. Responses were set as HCPs and aggregation and linear model was selected in the DoE software.
Determination of dynamic binding capacity (DBC) of Protein A chromatography runs

DBC of each column was performed by CHO supernatant with three minutes of residence time. With the mAb flowing through on the column, increase in the UV signal was recognized and the protein concentration of the fractions around this signal was analyzed by Biacore-T200 for the DBC. Until the fraction concentration was less than $0.1 \mathrm{mg} / \mathrm{ml}$, the total volume of fractions was determined as the maximum volume bounded the column. The collected volume was multiplied by $\mathrm{CHO}$ supernatant concentration to determine DBC. 
Equilibration buffer was $30 \mathrm{mM}$ citrate, $150 \mathrm{mM} \mathrm{NaCl}$ of $\mathrm{pH} 7$ at 5 column volume (CV) for all columns. Post load wash was applied with $30 \mathrm{mM}$ citrate, $1 \mathrm{M} \mathrm{NaCl}$ of $\mathrm{pH} 7$ and $10 \mathrm{mM}$ Citrate of $\mathrm{pH} 7$ at 5 $\mathrm{CV}$, respectively. The bound $\mathrm{mAb}$ was eluted by $10 \mathrm{mM}$ citric acid of pH 3.5 at $7 \mathrm{CV}$ which was determined by HTPD technology.

Cation exchange resin screening with high-throughput technology

Experimental template was designed with Design Expert Software 12 (Stat-Ease. Inc., Minneapolis. MN). $100 \mu \mathrm{l}(0.5 \mathrm{~cm}$ x 0.5 cm) OPUS ${ }^{\circledR}$ PipetColumns (Repligen Corporation) were used for screening with electronic Multipipette ${ }^{\circledR}$ E3x (Eppendorf). Two different CEX resin types were used; strong and weak. Linear model with L-Optimal was selected in the software. Factors entered in Design Expert Software 12 (Stat-Ease. Inc., Minneapolis. MN) were concentration of equilibration/wash buffer which is between 10 $\mathrm{mM}-50 \mathrm{mM}$ sodium phosphate, $\mathrm{pH}$ which is between 4 - 5, and two different resin types. Responses in this study were HCPs and aggregation.

Resins were regenerated with $2 \mathrm{M} \mathrm{NaCl}$ at $5 \mathrm{CV}$ and equilibrated with using design layout $\mathrm{pH}$ and ionic strength at $8 \mathrm{CV}$. Loading was done at flow-through mode at a concentration of $300 \mathrm{mg}$ protein purified from Protein A column. After loading, column was applied at $1 \mathrm{CV}$. Confirmation runs were done with the Äkta Avant 25 from Cytiva was used with selected $1 \mathrm{ml} C E X$ column. The column regeneration was applied with $2 \mathrm{M} \mathrm{NaCl}$ at $5 \mathrm{CV}$. Equilibration buffer was $20 \mathrm{mM}$ sodium phosphate $\mathrm{pH} 4.5$ at $5 \mathrm{CV}$ which was determined by HTPD technology. Post load wash was applied with the equilibration buffer at $1 \mathrm{CV}$.

\section{Analytical characterization}

ELISA was performed by manufacturers' protocols used for the quantification of CHO HCP (\#F550) and rPA (\#F600) from Cygnus Technologies. The analysis of aggregates and fragments were performed by Waters BEHSEC200 SEC column using Waters SEC-UPLC. The concentration of mAb was determined by the Nanodrop ${ }^{\mathrm{TM}}$ One Microvolume UV-Vis Spectrophotometer. Biacore-T200 was used for measurement of protein concentrations for DBC calculation.

\section{Results and Discussion}

In this study, firstly, HTPD technology was coupled with DoE tools to find an appropriate elution buffer for Protein A chroma- tography. Screened process related parameters were buffer type (acetic acid, citric acid, sodium acetate), the concentration of buffer (10 mM -150 mM), pH (3-3.8) and three different Protein A resins. After finding out the optimum condition which provides the lowest aggregate and HCP, material for CEX was prepared and HTPD technology was again coupled with DoE tools for cation exchange resin screening. Conditions like the concentration of flow-through sodium phosphate-based buffer (10 mM - $50 \mathrm{mM}$ ), working $\mathrm{pH}$ and comparison of strong and weak cation exchange resin were screened. After finding suitable parameters for CEX, scale-up strategy was performed with $1 \mathrm{ml}$ prepacked CEX resin.

Determination of suitable elution buffer with high-throughput technology

In order to find the most appropriate elution buffer providing the highest yield and lowest impurities, following conditions given in table 2, were run in $0.1 \mathrm{ml}$ Protein A resin columns. Linear model was applied and a total of 41 experiments were run and analysis was carried out through Analysis of Variance (ANOVA) in Design Expert software. The titer of the biosimilar mAb TUR02 in the clarified CHO supernatant was $2.5 \mathrm{mg} / \mathrm{ml}$ and the HCP content was 513575 ppm.

Elution from the Protein A resin was carried out using a low $\mathrm{pH}$ buffer since low pH directly affect the binding sites reducing the affinity. In Protein A chromatography, the binding region of $\mathrm{mAb}$ faces histidyl residues of Protein A ligand. When low $\mathrm{pH}$ values (between pH 3 and 4) are used in the elution step [8], due to the positive charge on the histidyl residues, a weak hydrophobic interaction between Protein A ligand and mAb occurs providing a successful elution [23]. However, low pH can induce the Protein Aggregation which can cause problems in the yield and quality [8]. In addition to $\mathrm{pH}$, the elution buffer type and ionic strength have major importance to get higher yields of mAbs [9] since the interaction between a mAb and Protein A ligand depends on the specific ionic charge, hydrogen or hydrophobic bond [10]. Typically, sodium citrate, arginine or glycine- $\mathrm{HCl}$ are used for Protein A elution buffer $[8,10,11]$.

Low pH principle is the most commonly used way to elute the $\mathrm{mAb}$ from the resin. During the screening of elution conditions, $\mathrm{pH}$ range was kept narrow on purpose to find the best elution condition that is suitable for the base matrix and Protein A ligand [18]. For this molecule, the results showed that buffer type has more af- 


\begin{tabular}{|c|c|c|c|}
\hline Resin Number & Elution Buffer Condition & Resin Number & Elution Buffer Condition \\
\hline $\mathrm{R} 1$ & 10mM Acetic Acid pH 3 & $\mathrm{R} 1$ & 150mM Acetic Acid pH 3.8 \\
\hline R3 & 10mM Acetic Acid pH 3 & R3 & 150mM Acetic Acid pH 3.8 \\
\hline $\mathrm{R} 2$ & 10mM Acetic Acid pH 3 & $\mathrm{R} 2$ & 150mM Acetic Acid pH 3.8 \\
\hline $\mathrm{R} 1$ & 10mM Acetic Acid pH 3.8 & $\mathrm{R} 1$ & 150mM Citric Acid pH 3 \\
\hline R3 & 10mM Acetic Acid pH 3.8 & R3 & 150mM Citric Acid pH 3 \\
\hline $\mathrm{R} 2$ & 10mM Acetic Acid pH 3.8 & $\mathrm{R} 2$ & 150mM Citric Acid pH 3 \\
\hline $\mathrm{R} 1$ & 10mM Citric Acid pH 3 & $\mathrm{R} 1$ & 150mM Citric Acid pH 3.8 \\
\hline R3 & 10mM Citric Acid pH 3 & R3 & 150mM Citric Acid pH 3.8 \\
\hline $\mathrm{R} 2$ & 10mM Citric Acid pH 3 & $\mathrm{R} 2$ & 150mM Citric Acid pH 3.8 \\
\hline $\mathrm{R} 1$ & 10mM Citric Acid pH 3.8 & R1 & 150mM Sodium Acetate pH 3 \\
\hline $\mathrm{R} 3$ & 10mM Citric Acid pH 3.8 & R3 & 150mM Sodium Acetate pH 3 \\
\hline $\mathrm{R} 2$ & 10mM Citric Acid pH 3.8 & $\mathrm{R} 2$ & 150mM Sodium Acetate pH 3 \\
\hline $\mathrm{R} 1$ & 10mM Sodium Acetate pH 3 & $\mathrm{R} 1$ & 150mM Sodium Acetate pH 3.8 \\
\hline R3 & 10mM Sodium Acetate pH 3 & R3 & 150mM Sodium Acetate pH 3.8 \\
\hline $\mathrm{R} 2$ & 10mM Sodium Acetate pH 3 & $\mathrm{R} 2$ & 150mM Sodium Acetate pH 3.8 \\
\hline $\mathrm{R} 1$ & 10mM Sodium Acetate pH 3.8 & R3 & 80mM Citric Acid pH 3.4 \\
\hline R3 & 10mM Sodium Acetate $\mathrm{pH} 3.8$ & R3 & 80mM Citric Acid pH 3.4 \\
\hline $\mathrm{R} 2$ & 10mM Sodium Acetate $\mathrm{pH} 3.8$ & R3 & 80mM Citric Acid pH 3.4 \\
\hline $\mathrm{R} 1$ & 150mM Acetic Acid pH 3 & R3 & 80mM Citric Acid pH 3.4 \\
\hline R3 & 150mM Acetic Acid pH 3 & R3 & 80mM Citric Acid pH 3.4 \\
\hline $\mathrm{R} 2$ & 150mM Acetic Acid pH 3 & R3 & 80mM Citric Acid pH 3.4 \\
\hline
\end{tabular}

Table 2: Experimental template for selecting of elution buffer.

fect between $\mathrm{pH} 3$ - 3.8. The aggregation levels changed between $0.2 \%$ and $40 \%$ in acetic acid-based buffer screening (Figure 2) whereas sodium acetate and citric acid buffers provided maximum $1 \%$ aggregate level for this molecule. Also, we observed that both controlled pore glass (R3) and high flow agarose beads (R2) resins had shown high aggregation level at the high acetic acid concentration and at $\mathrm{pH}$ 3. It was observed that methacrylic polymer (R1) which has high hydrophilicity to minimize non-specific binding [19] showed lower aggregation level compared to R2 and R3 in acetic acid buffer. In the experimental template, for sodium acetatebased, high concentration of buffer content was not screened due to selection of model in the software.

The monoclonal antibodies have tendency to aggregate under certain conditions for this reason aggregation remains a major focus in the therapeutic mAb production. The release strategy from Protein A chromatography is based on the acidic conditions and low $\mathrm{pH}$ conditions. However, for many mAbs, acidic conditions and low $\mathrm{pH}$ conditions can be the typical cause of aggregation during Protein A chromatography [8]. Protein A-Fc interactions may lead to destabilization of mAb structure while increasing the tendency to aggregate [21]. Not only low $\mathrm{pH}$ condition has aggregation challenges, but also the phenomenon of desorption from Protein A resin can destabilize the $\mathrm{mAb}$ [1]. In therapeutic mAbs, aggregate is not desirable because of their possible immunogenic effects on patients [22]. Although a biosimilar mAb which has high tendency to aggregate was used in this study, the aggregate levels after three Protein A resins were not too high as shown in figure 2.

Not only aggregation level, but also HCPs reduction is important for selection of buffer type. HCPs results are given in figure 3. Interestingly, highest HCP reduction was observed at $150 \mathrm{mM}$ acetic acid at $\mathrm{pH} 3$ where highest aggregation level was observed. All conditions except $80 \mathrm{mM}$ citric acid at $\mathrm{pH} 3.4$ had significant amount of HCP reduction for Protein A chromatography. 

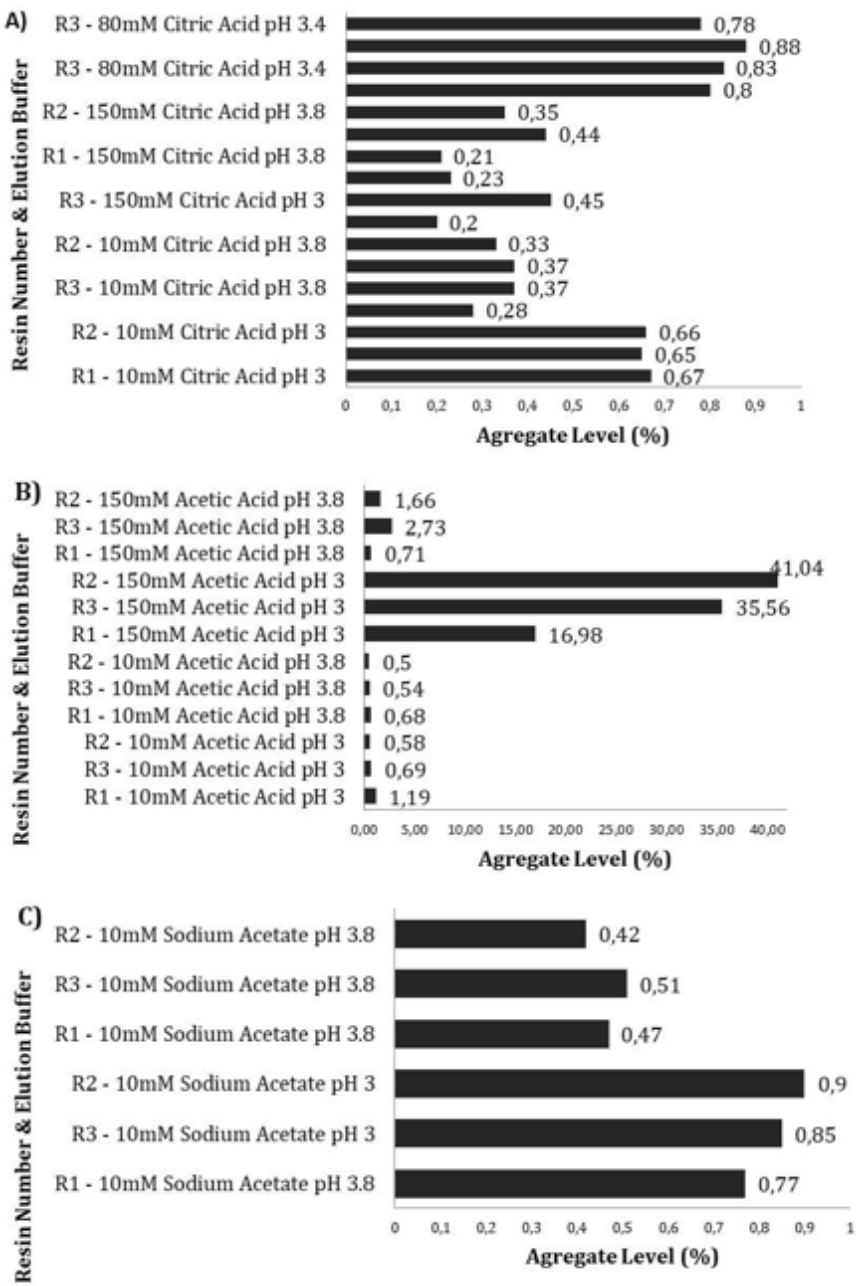

Figure 2: Aggregation results after elution buffer screening; a) citric acid buffer; b) acetic acid buffer; c) sodium acetate buffer.

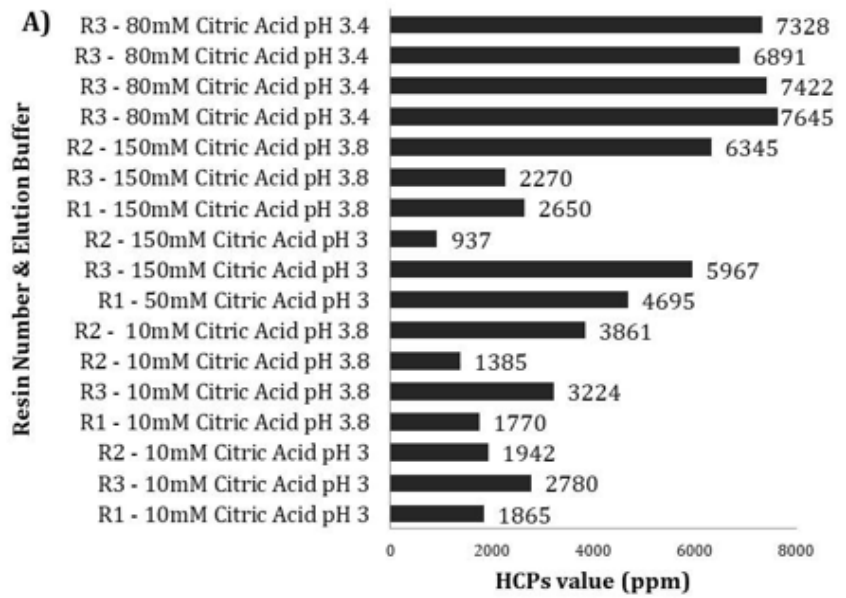




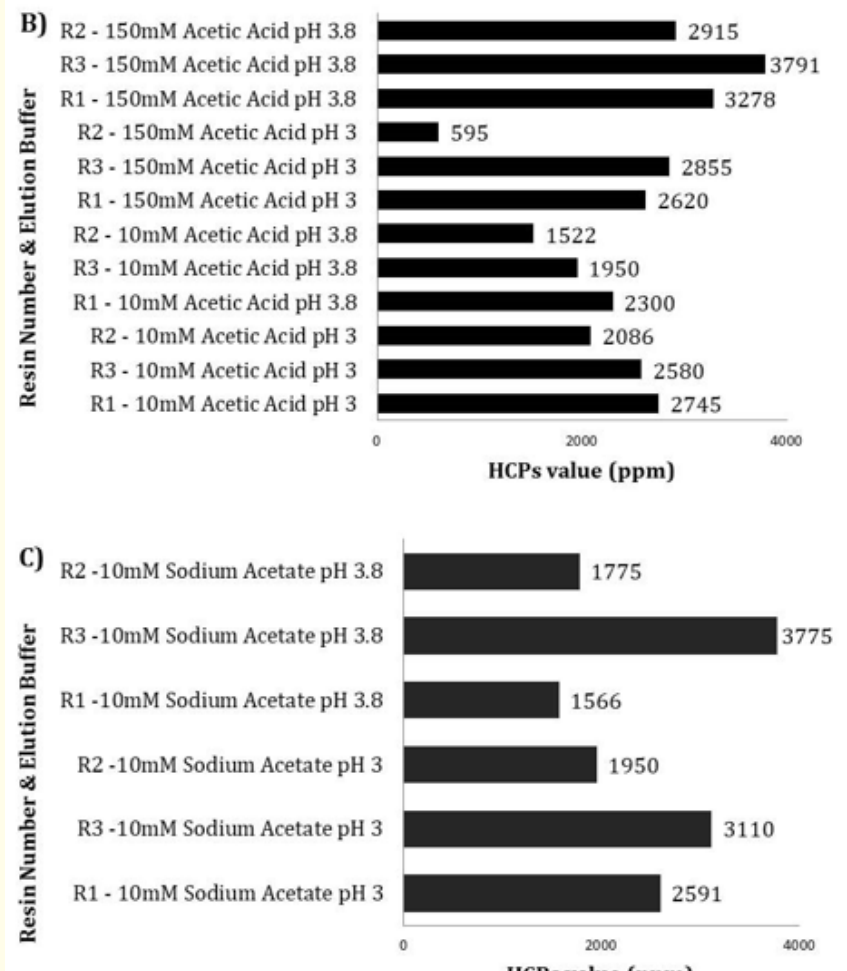

Figure 3: HCPs results after elution buffer screening; a) citric acid buffer; b) acetic acid buffer; c) sodium acetate buffer.

Since in the citric acid-based screening, all conditions have suitable for aggregation level (below 0.8\%), $10 \mathrm{mM}$ citric acid and $\mathrm{pH}$ 3.5 was selected as the best suitable elution buffer focusing on HCP. Both HCP and aggregate levels can be further improved in the polishing chromatography. Resin 1 (methacrylic polymer) was selected and lab-scale experiment in AKTA chromatography was done.

For $1 \mathrm{ml}$ column run, a $3 \mathrm{~L}$ bioreactor run was done and the titer was measured as $3.1 \mathrm{mg} / \mathrm{ml}$ and the HCPs analysis of the CHO harvest was 601633.93 ppm. Firstly, the dynamic binding capacity of Resin 1 was measured and calculated as 60 which is very high due to the industrial standards. The base matrix of methacrylic polymer can minimize the non-specific binding by increased hydrophilicity property which can provide high DBC [19]. Figure 4 shows the chromatogram of Resin 1 at selected elution buffer.

After running the Protein A chromatogram, the aggregate and HCP levels were measured in the $1 \mathrm{ml}$ column to compare with the $0.1 \mathrm{ml}$ micro-volume column, given in table 3 .
The aggregate levels in $0.1 \mathrm{ml}$ column and $1 \mathrm{ml}$ column were found very close to each other showing the success of the HTPD technology. The HCP value was even lower in the $1 \mathrm{ml}$ pre-packed column. These results proved the scalability of the HTPD technology for Protein A chromatography.

Cation exchange resin screening with high-throughput technology

After Protein A chromatography studies, a pool was prepared which has a titer of $17.8 \mathrm{mg} / \mathrm{ml}$ TUR02 and HCPs content was measured as 2370 ppm before loading to the $0.1 \mathrm{ml}$ pipette columns. The factors that were entered in DoE were $\mathrm{pH}$, ionic strength and resin type. A total of 20 runs together with its analytical characterization results are given in table 4 .

During CEX study, overloading chromatography was applied with the differential binding between the product and impurities [23]. Working $\mathrm{pH}$ range was 4-5 which means that mAb had posi- 


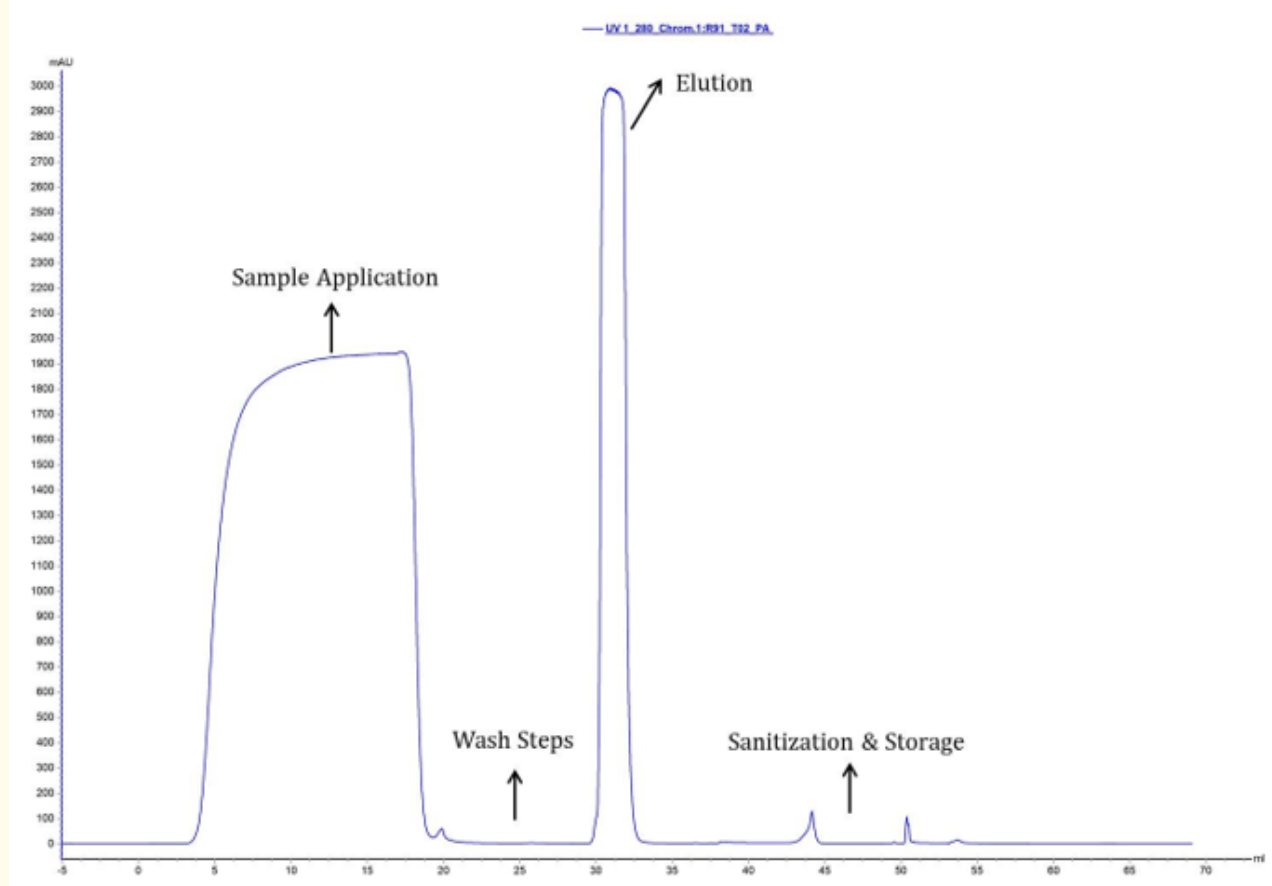

Figure 4: Protein A chromatogram of Resin 1 in $1 \mathrm{ml}$ column.

\begin{tabular}{|c|c|c|}
\hline & R1 in 0.1 ml micro-volume column & R1 in 1 ml prepacked column \\
\hline Aggregate Value (\%) & 0.67 & 0.76 \\
\hline Host Cell Protein Value (ppm) & 1865 & 326 \\
\hline
\end{tabular}

Table 3: Comparison between $0.1 \mathrm{ml}$ micro-volume column and $1 \mathrm{ml}$ prepacked column with selected elution buffer at $10 \mathrm{mM}$ Citric Acid pH 3.

\begin{tabular}{|c|c|c|c|c|c|}
\hline Factor 1 pH & Factor 2 Ionic Strength (mM) & Factor 3 Resin Type & Yield (\%) & Aggregation (\%) & HCPs (ppm) \\
\hline 4.75 & 49.6774 & Weak CEX Resin & 69 & 1.43 & 622 \\
\hline 5 & 10 & Weak CEX Resin & 72 & 4.43 & 842 \\
\hline 4.75 & 49.6774 & Weak CEX Resin & 70 & 1.46 & 664 \\
\hline 4.37 & 50 & Strong CEX Resin & 67 & 1.06 & 1589 \\
\hline 5 & 20 & Strong CEX Resin & 73 & 5.26 & 915 \\
\hline 4.5 & 30 & Weak CEX Resin & 89 & 0.58 & 775 \\
\hline 4.5 & 30 & Weak CEX Resin & 81 & 0.59 & 819 \\
\hline 4.5 & 30 & Strong CEX Resin & 73 & 1.10 & 1019 \\
\hline 4.5 & 30 & Strong CEX Resin & 80 & 1.10 & 1181 \\
\hline 5 & 10 & Weak CEX Resin & 88 & 4.98 & 915 \\
\hline 4 & 50 & Weak CEX Resin & 83 & 0.50 & 1622 \\
\hline 4 & 50 & Weak CEX Resin & 80 & 0.65 & 1357 \\
\hline 5 & 50 & Strong CEX Resin & 82 & 5.42 & 657 \\
\hline 4 & 50 & Weak CEX Resin & 79 & 0.41 & 1305 \\
\hline 4.25 & 10 & Weak CEX Resin & 73 & 0.44 & 1403 \\
\hline 4.5 & 30 & Strong CEX Resin & 89 & 0.92 & 855 \\
\hline 4 & 10 & Strong CEX Resin & 72 & 0.84 & 2245 \\
\hline 4.5 & 30 & Weak CEX Resin & 69 & 0.58 & 735 \\
\hline 5 & 50 & Strong CEX Resin & 90 & 5.68 & 815 \\
\hline 4 & 35.2 & Strong CEX Resin & 70 & 0.83 & 1700 \\
\hline 4 & 10 & Strong CEX Resin & 77 & 0.79 & 1802 \\
\hline
\end{tabular}

Table 4: The experiment template for CEX resin screening. 
tively charge. CEX resins have negatively charged particle, so they are supposed to bind positively charged molecules, because of the pI value of $\mathrm{mAb}$; the product was also bound to the resin based on DBC. In this technique, impurities were bound to the resin as well as the mAb. DoE analysis was performed by ANOVA with putting the responses. Aggregate and HCPs graphs based on factors were generated in the software presented in Figure 5. Resin type has a critical role for both reduction of aggregation and HCPs. Because both impurities bind to the resin with overloading, resin type was observed as significant due to binding of the resin. The results showed that strong CEX resin is suitable for removal of impurities. Non-covalently bound aggregates can be formed between weak protein-protein interactions such as hydrophobic/hydrophilic at short distance of protein structure [24]. A weak non-covalent reversible aggregation has been observed for the mAb molecule which is anti-VEGF given in Moore., et al. [25]. The reversibility usually has equilibrium between the monomer and aggregation percentage. This equilibrium can shift by changing $\mathrm{pH}$ or decreasing the mAb concentration. The mAb used in this study, has high aggregate at the high $\mathrm{pH}$ as 5.26, 5.42, and 5.68 in strong CEX resin at pH 5 (Table 4). Figure 5 shows the comparison between weak and strong CEX resins in terms of HCPs and HMWs.

The DOE results proved that strong CEX resin provides to keep both HCPs and aggregates at low levels at pH 4.5 and 38-mM sodium phosphate buffer. A confirmation run was done in $1 \mathrm{ml}$ CEX column in AKTA chromatography at these selected conditions and the responses were very close to each other as given in table 5 .

As a result, HCPs reduction was observed from $2369 \mathrm{ppm}$ to $234.4 \mathrm{ppm}$ and aggregation reduction level from $0.76 \%$ to $0.32 \%$
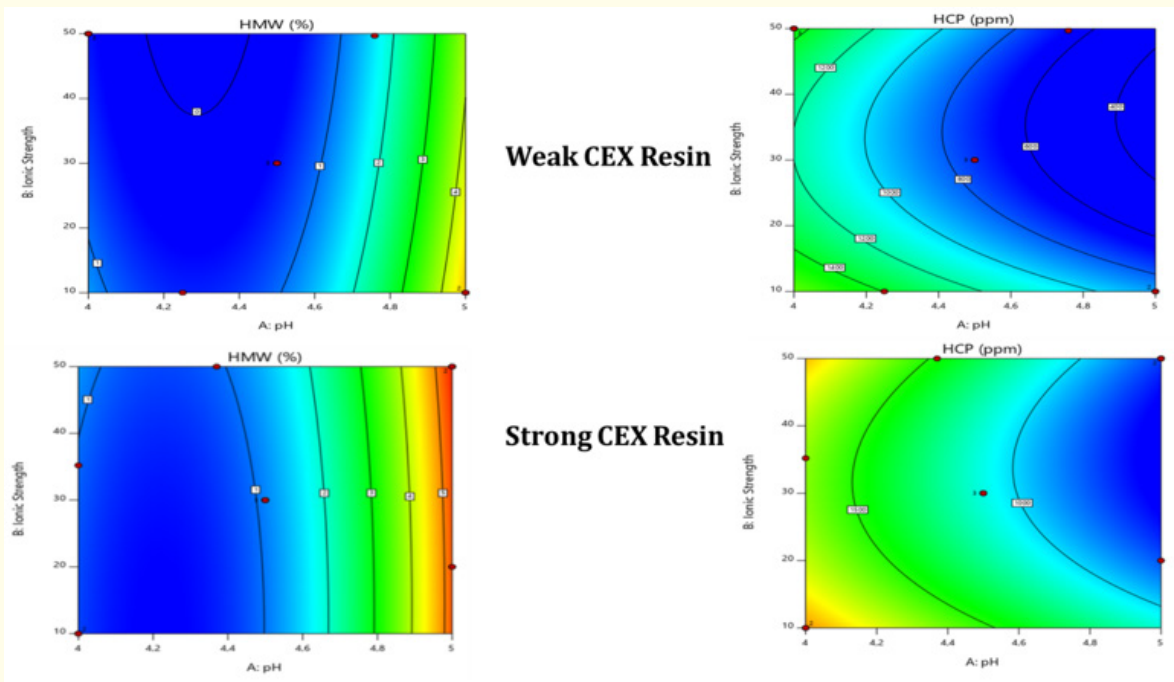

Figure 5: Evaluation of High-Throughput CEX chromatography screening.

\begin{tabular}{|c|c|c|c|c|c|c|}
\hline & $\begin{array}{c}\text { Factor } 1 \\
\text { pH }\end{array}$ & $\begin{array}{c}\text { Factor } 2 \\
\text { Ionic Strength (mM) }\end{array}$ & $\begin{array}{c}\text { Factor } 3 \\
\text { Resin Type }\end{array}$ & $\begin{array}{c}\text { Yield } \\
\text { (\%) }\end{array}$ & $\begin{array}{l}\text { Aggregation } \\
\text { (\%) }\end{array}$ & $\begin{array}{l}\text { HCPs } \\
\text { (ppm) }\end{array}$ \\
\hline Predicted values by DoE program & \multirow{4}{*}{4.5} & \multirow{4}{*}{38} & \multirow{4}{*}{$\begin{array}{c}\text { Strong } \\
\text { CEX Resin }\end{array}$} & 77 & 0.41 & 713 \\
\hline $\begin{array}{l}\text { Experiment } 1 \text { by using Micro-volume Column } \\
\qquad(0,1 \mathrm{ml})\end{array}$ & & & & 97 & 0.52 & 612 \\
\hline $\begin{array}{c}\text { Experiment } 2 \text { by using Äkta Avant } 25 \\
1 \mathrm{ml} \text { prepacked column with Residence Time } 25 \mathrm{sec}\end{array}$ & & & & 90 & 0.44 & 375 \\
\hline $\begin{array}{c}\text { Experiment } 3 \text { by using Äkta Avant } 25 \\
1 \mathrm{ml} \text { prepacked column with Residence Time } 3 \text { min }\end{array}$ & & & & 94 & 0.32 & 234 \\
\hline
\end{tabular}

Table 5: Comparison of lab-scale and micro-volume column runs for confirmation. 
in $1 \mathrm{ml}$ column. In both $0.1 \mathrm{ml}$ micro-volume columns and $1 \mathrm{ml}$ prepacked column, impurities like aggregate and HCPs values were found to be close to each other which mean that HTPD technology was scalable for CEX application of TUR02 molecule. Also, similarity of yield value showed us the purification process was optimized.

\section{Conclusion}

Coupling HTP technology platform with DoE tools, processes for Protein A and cation exchange chromatography were developed to be used in biosimilar mAb TUR02 production. With increasing prices of mAb-drugs, biosimilar mAb development became very competitive nowadays. For this reason it is very important to develop a cost-effective process in fast manner. Using micro-volume columns provided us to screen a lot of parameters using low amount of material in a shorter period of time. The downstream process development period can be decreased by $90 \%$ using HTP technology. In this study, firstly, a large number of parameters were screened for finding out appropriate elution buffer for high HCP and aggregate removal. $10 \mathrm{mM}$ citric acid, pH 3.5 and a base matrix of methacrylic polymer resin were selected for Protein A chromatography. These conditions were also applied with $1 \mathrm{ml}$ pre-packed column to demonstrate the success of the scalability of HTP technology. After Protein A chromatography, cation exchange chromatography was chosen as a polishing chromatography. A large parameter screening for cation exchange conditions was applied to further remove the impurities. In the flow-through mode, strong cation exchange resin, $38 \mathrm{mM}$ sodium phosphate and $\mathrm{pH} 4.5$ provided the highest aggregate and HCP reduction. Scalability of the process was successfully proven using $1 \mathrm{ml}$ pre-packed column. With these conditions, the aggregate and HCP levels were found as 0,52 and 612 and 0,32 and 234 for $0.1 \mathrm{ml}$ and $1 \mathrm{ml}$ columns, respectively. Qualitative and quantitative comparability was also seen with micro-volume column and laboratory scale columns, for example, the yield was 97\% in micro-volume, whereas the yield was observed 94\% in $1 \mathrm{ml}$ prepacked column.

\section{Acknowledgements}

The authors thank Ahmet Emin Atik and Yiğit Erdemgil for the analytical characterization support. Special thanks are given to the Chairman of the Board and General Manager, Tunç TURGUT from Turgut Pharmaceuticals. This work has been partly supported by programs of the TUBITAK/TEYDEB - 1509 (Project No: 9170058) (International Industry R\&D Projects Support Program) and Eureka/Euripides (SR4SB).

\section{Conflict of Interest}

The authors have no conflicts of interest to declare.

\section{Bibliography}

1. Gronemeyer Petra., et al. "Trends in Upstream and Downstream Process Development for Antibody Manufacturing". Bioengineering 1.4 (2014): 188-212.

2. Xu Zhihao., et al. "Process Development For Robust Removal Of Aggregates Using Cation Exchange Chromatography In Monoclonal Antibody Purification With Implementation of Quality By Design". Preparative Biochemistry and Biotechnology 42.2 (2012): 183-202.

3. Treier Katrin., et al. "High-Throughput Methods for Miniaturization and Automation of Monoclonal Antibody Purification Processes”. Biotechnology Progress 28.3 (2012): 723-732.

4. Shukla Abhinav A and Peter Hinckley. "Host Cell Protein Clearance during Protein a Chromatography: Development of an Improved Column Wash Step". Biotechnology Progress 24.5 (2008): 1115-1121.

5. Liu, Hui F., et al. "Recovery and Purification Process Development for Monoclonal Antibody Production". MAbs 2.5 (2010): 480-499.

6. Kelley Brian. "Downstream Processing Of Monoclonal Antibodies: Current Practices And Future Opportunities". Process Scale Purification of Antibodies (2017): 1-21.

7. Mazzer Alice R., et al. "Protein A Chromatography Increases Monoclonal Antibody Aggregation Rate during Subsequent Low PH Virus Inactivation Hold". Journal of Chromatography A 1415 (2015): 83-90.

8. Mahler Hanns-Christian., et al. "Protein Aggregation: Pathways, Induction Factors and Analysis". Journal of Pharmaceutical Sciences 98.9 (2009): 2909-2934.

9. Liu Hui F., et al. "Recovery and Purification Process Development for Monoclonal Antibody Production". MAbs 2.5 (2010): 480-499.

10. Thermo Scientific. Optimize Elution Conditions for Immunoaffinity Purification, TECH TIP \# 27 / TR0027.1, (2009).

11. GE Healthcare. Mahler Hanns-Christian., et al. "Protein Aggregation: Pathways, Induction Factors and Analysis". Journal of Pharmaceutical Sciences 98.9, 2009): 2909-2934. 
12. GoldBio. Plain \&amp; Crosslinked Agarose Bead Informational, FM-000008 / TD-I Revision 2.0 (2019).

13. Kumar A., et al. "Polymer Displacement/Shielding in Protein Chromatography". Journal of Chromatography B: Biomedical Sciences and Applications 741.2 (2000): 103-113.

14. Nogal Bartek., et al. "Select Host Cell Proteins Coelute with Monoclonal Antibodies in Protein a Chromatography". Biotechnology Progress 28.2 (2012): 454-458.

15. Hober Sophia., et al. "Protein A Chromatography for Antibody Purification". Journal of Chromatography B 848.1 (2007): 4047.

16. Nogal Bartek., et al. "Select Host Cell Proteins Coelute with Monoclonal Antibodies in Protein a Chromatography". Biotechnology Progress 28.2 (2012): 454-458.

17. Connell-Crowley Lisa., et al. "Cation Exchange Chromatography Provides Effective Retrovirus Clearance for Antibody Purification Processes". Biotechnology and Bioengineering 109.1 (2011): 157-165.

18. Vázquez-Rey María and Dietmar A Lang. "Aggregates in Monoclonal Antibody Manufacturing Processes". Biotechnology and Bioengineering 108.7 (2011): 1494-1508.

19. McCaw Tyler R., et al. "Evaluation of a Novel MethacrylateBased Protein a Resin for the Purification of Immunoglobulins and Fc-Fusion Proteins". Biotechnology Progress 30.5 (2014): 1125-1136.

20. "Ion Exchange Chromatography". Bio.

21. Flatman Stephen., et al. "Process Analytics for Purification of Monoclonal Antibodies". Journal of Chromatography B 848.1 (2007): 79-87.

22. Buchner Johannes., et al. "Alternatively Folded States of an Immunoglobulin". Biochemistry 30.28 (1991): 6922-6929.

23. Sharma Basant. "Immunogenicity of Therapeutic Proteins. Part 3: Impact of Manufacturing Changes". Biotechnology Advances 25.3 (2007): 325-331.

24. Tan Zhijun., et al. "On-Column Disulfide Bond Formation of Monoclonal Antibodies during Protein A Chromatography Eliminates Low Molecular Weight Species and Rescues Reduced Antibodies". MAbs 12.1 (2020): 1829333.
25. Mahler Hanns-Christian., et al. "Induction and Analysis of Aggregates in a Liquid IgG1-Antibody Formulation". European Journal of Pharmaceutics and Biopharmaceutics 59.3 (2005): 407-417.

Volume 5 Issue 10 October 2021

(C) All rights are reserved by Deniz Baycin Demirhan., et al. 